\title{
CONVERGENCIA \\ Y DIVERGENCIA \\ DE LOS REPERTORIOS \\ ANTROPONÍMICOS \\ BRASILEÑO \\ Y ESPAÑOL
}

\section{CONVERGÊNCIA E DIVERGÊNCIA DOS REPERTÓRIOS ANTROPONÍMICOS BRASILEIRO E ESPANHOL}

CONVERGENCE AND DIVERGENCE OF THE BRAZILIAN AND SPANISH ANTHROPONYMIC REPERTORIES

\author{
Carmen Fernández Juncal* \\ Universidad de Salamanca \\ Márcia Sipavicius Seide**
}

Universidade Estadual do Oeste do Paraná

\begin{abstract}
RESUMEN: Este trabajo indaga en los aspectos convergentes y divergentes de los repertorios antroponímicos español y brasileño. A partir de los datos generados por organismos estatales (INE e IBGE) y considerando los nombres más populares, se señala la evolución de ambos catálogos a lo largo de las uúltimas nueve décadas, desde una gran convergencia a una divergencia notable, en línea con las tendencias globales detectadas en otras sintopías. No obstante, las similitudes en general son muy destacadas, como corresponde a repertorios de lenguas muy próximas, cuyas trayectorias históricas y culturales se han desarrollado paralelamente. PALABRAS CLAVE: Socionomástica. Antroponomástica Comparada. Brasil. España.
\end{abstract}

RESUMO: O foco deste artigo é investigar os aspectos convergentes e divergentes dos repertórios antroponímicos espanhóis e brasileiros. A partir dos dados gerados por instituições nacionais oficiais (INE e IBGE) e considerando os nomes mais populares, se indica a evolução de ambos os catálogos ao longo das últimas nove décadas de uma grande convergência a uma notável divergência, resultado que se alinha com as tendências globais em outras sintopias. No entanto, a semelhanças em geral são muito destacadas, como é de se esperar de repertórios de línguas muito próximas, cujas trajetórias históricas e culturais se desenvolveram em paralelo. PALAVRAS- CHAVE: Socionomástica. Antroponomástica Comparada. Brasil. Espanha.

\footnotetext{
*Profesoratitulardel Departamentode Lengua Española,E-mail:cjuncal@usal.es.

** Profesora del "Programa de Pós-Graduação em Letras" de Unioeste, campus de Cascavel y del "Colegiado de Letras" docampusde Marechal CândidoRondon. E-mail: Marcia.seide@unioeste.br.
} 
ABSTRACT: This work investigates the convergent and divergent aspects of the Spanish and Brazilian anthroponymic repertoires. Based on the data generated by state agencies (INE and IBGE) and considering the most popular names, it points out the evolution of both catalogues along the last nine decades, from a great convergence to a remarkable divergence, in line with the global trends detected in other countries. However, the general similarities are very striking, as befits repertoires of languages that are very close to each other, whose historical and cultural trajectories have developed in parallel.

KEYWORDS: Socionomastics. Comparative Anthroponomastics. Brazil. Spain.

\section{INTRODUCCIÓN}

La investigación presentada en este artículo se inserta en la Onomástica, área de estudio dedicada a la investigación de los nombres propios. De entre los diversos tipos de nombres propios, este artículo pone su foco de atención en los antropónimos y, dentro de estos, en los llamados nombres de pila, nombres oficiales que forman parte del nombre civil de la persona y son usados para su individualización (AMARAL; SEIDE, 2020, p.74).

Aunque los nombres de persona ocupan un lugar importante en el uso lingüístico y cumplen funciones más allá de la identificación de persona (función simbólica, función identitaria), la Antroponomástica es una disciplina que ha sido dejada de lado dentro de la investigación lingüística y de la enseñanza de lenguas (JOSEPH, 2004). Por su propia configuración y por los fines que persigue se trata de un área de conocimiento eminentemente interdisciplinar, que debe emplear herramientas de otras especialidades para poder llevar a cabo su tarea (SEIDE, 2016). Dentro de esta disciplina se distinguen diversos campos de investigación. Destacaremos dos que están íntimamente asociados: por una parte, la Socionomástica examina la interrelación entre la atribución nominal (la elección de los nombres, no solo de persona, pero principalmente de persona) y diversos factores de tipo social que, en diferente medida, afectan a esta atribución ${ }^{1}$. Es el caso de los desplazamientos en los gustos dentro de la escala social, las modas, los cambios en los valores sociales o las tendencias estéticas, entre otros.

Por otra parte, la Antroponomástica Comparada tiene como objetivo el estudio contrastivo entre dos o más repertorios antroponímicos. Este ámbito de estudio está directamente ligado a la Lingüística Comparada, cuyo objetivo central es:

[...] to obtain results not only about the origin and development of languages, but also about their features which might be seen either as universal or as peculiar to each language and culture. In a similar manner, contrasting different social norms concerning people's first names can lead to a better comprehension of common and distinct features of names and their usage across languages and cultures. (SEIDE; PETRULIONĖ, 2018, p. 1203)

En lo que concierne a los múltiples usos antroponímicos en variadas lenguas y culturas, se pueden hacer comparaciones entre países limítrofes, países que comparten el mismo idioma, países con culturas y lenguas distintas o semejantes (SEIDE, 2020). En el caso de las lenguas involucradas en la investigación presentada en este artículo, se han elegido variedades y culturas semejantes cuyo análisis requiere procedimientos adecuados para que se puedan determinar con más precisión las similitudes y divergencias entre los idiomas que son objeto de comparación. No hay que olvidar que las prácticas onomásticas existen en todos los grupos humanos y que estas se ven afectadas por diferentes circunstancias: desde las condiciones externas (históricas, culturales) (LIEBERSON, 2000) hasta el propio sistema lingüístico, que permite o restringe diferentes desarrollos onomásticos.

Desde el punto de vista antroponímico comparado, dos lenguas cercanas presentan diferentes grados de convergencia y de divergencia, que varían gradualmente, desde la total semejanza, generadora de homonimia entre nombres, y termina en la total diferencia, en la existencia de nombres exclusivos en cada idioma. Con esta idea como punto de partida, se han adoptados procedimientos metodológicos específicos que se describen en la siguiente sección de este artículo.

${ }^{1}$ Para una introducción a este campo de investigación, ver. Frai (2016) y Ainiala, y Östman, (2017). 


\section{CUESTIONES METODOLÓGICAS}

La investigación que presentamos toma como fuentes dos repertorios antroponímicos: el elaborado por el Instituto Nacional de Estadística de España (INE, 2020) y el que proporciona el Instituto Brasileño de Geografía y Estadística (IBGE, 2020). Se trata de una información pública y abierta que ambas entidades abordan con diferente profundidad. En el caso del INE, se aportan, entre otros, datos sobre todos los nombres de residentes en el país con frecuencia igual o superior a 20 (se especifica en este caso el número de portadores y su edad promedio ${ }^{2}$ ), los 100 nombres más frecuentes para todo el territorio nacional con dos variantes: una que incluye los nombres compuestos y otra que los excluye, considerando sus componentes como unidades simples, los 50 nombres más habituales por década de nacimiento y los 100-150 nombres más frecuentes entre los recién nacidos desde 2002, año a año. Cuenta asimismo con una aplicación para consultas específicas acerca de nombres y apellidos concretos. El IBGE también cuenta con una aplicación semejante y facilita información individualizada sobre los nombres que tengan frecuencia superior a 20 (junto con su distribución geográfica), además del porcentaje de población que los tienen como denominación propia. Sin embargo, solo ofrece como listados de frecuencia los 20 primeros nombres por década (desde antes de 1930) y los 20 más populares en conjunto.

Esta discrepancia en el funcionamiento de ambas instituciones ha supuesto una limitación para los intereses de este estudio, ya que hemos contado con un catálogo condicionado por algunas restricciones. Partimos, por lo tanto, de listados de 20 antropónimos por décadas y sexos, lo que nos ofrece una cifra total de 720 nombres, que incluyen, como veremos, términos repetidos. Para compatibilizar los datos de frecuencia absoluta y relativa que se presentan en las dos plataformas, y como explicaremos con más detalle, hemos transformado los datos en bruto del número de usuarios que nos proporciona el INE en datos proporcionales (empleo del nombre por millón de habitantes) de forma que podamos armonizarlos con la información que aporta el IBGE.

Por otra parte, los procesos de contabilización y comparación de los dos repertorios han sido afectados por dos hechos. En primer lugar, en la lista brasileña aparecen variantes de un mismo étimo; la lista española global también los incluye, pero solo una variante está en las primeras posiciones. Eso nos obliga a contabilizar las variantes como dos nombres diferentes, respetando la decisión del instituto, pero como un solo nombre a la hora de establecer el contraste con el nombre español. Es lo que ocurre con Luis y Luiz respecto a Luis, Manuel y Manoel respecto a Manuel, Lúcia y Luzia respecto a Lucía y Andrea y Andreia respecto a Andrea. Para otras cuestiones que hemos abordado en este trabajo no ocultamos la dificultad que ha supuesto establecer los límites precisos entre variantes de un mismo antropónimo (Luis y Luiz), y antropónimos que comparten el mismo étimo, pero podemos considerar como diferentes antropónimos (Julián y Juliano o, volviendo al caso anterior, Luzia y Lúcia, por ejemplo). Además de la ayuda de la fonética (no tanto de la ortografía), se pueden establecer esos límites, que, no obstante, pasan siempre por la conciencia y el conocimiento de los propios usuarios sobre esta cuestión. La intuición de los hablantes en la atribución nominal puede ayudarnos a fijar esa distinción, que desde el punto de vista lingüístico es sutil, pero resulta clara desde la percepción de los no especialistas (FERNÁNDEZ JUNCAL; HERNÁNDEZ MUÑOZ, 2019).

En segundo lugar, la nómina en español incluye los nombres compuestos mientras que la brasileña solo contiene nombres simples. Esto ha supuesto una adaptación de los primeros respecto a los segundos, de forma que se reconocen como nombres comunes si al menos poseen un solo elemento compartido; quedan excluidos de esta decisión los antropónimos María y José, cuya presencia en los compuestos españoles es mayoritaria y cuya contabilización distorsionaría los resultados.

Para el análisis detallado de los antropónimos y para considerar la equivalencia entre un nombre español y un nombre portugués se ha utilizado el criterio etimológico. Utilizando esa pauta, el nombre Jorge, cuya grafía es idéntica en ambos idiomas, es un nombre equivalente, un caso típico de homonimia, que impide determinar si estamos ante un nombre en español o en portugués. Nombres con pocas divergencias gráficas también han sido considerados un mismo nombre, como ocurre con, por ejemplo, los dos nombres Sônia y Sonia. El primero está en lengua portuguesa y lleva acento circunflejo, mientras que no lo lleva el segundo, ya que está en lengua española. Cuando la diferencia gráfica dentro de una lengua no supone un cambio de pronunciación, se han considerado variantes de un mismo nombre, como ocurre con los nombres Luiz y Luis en lengua portuguesa. Sin embargo, cuando dos nombres

\footnotetext{
${ }^{2}$ A este respecto, Weitman (1981) destaca que las inferencias que extraigamos del análisis socionomástico deben atribuirse a los electores de nombres y no a sus portadores.
} 
etimológicamente equivalentes presentaban divergencias acentuadas, han sido evaluados como nombres distintos, respetando la estimación que llevarían a cabo los mismos hablantes nativos de cada idioma, especialmente cuando ambas formas están disponibles en el mismo repertorio léxico, como es el caso de los nombres Adrián y Adriano.

Otro procedimiento adoptado específicamente para posibilitar la comparación entre los idiomas concierne a la perspectiva desde la cual se compararon los repertorios antroponímicos. Se hizo el análisis detallado de los datos desde la perspectiva española y desde la perspectiva brasileña; esto es, se examinó primero cómo serían evaluados por hablantes nativos de España los nombres de IBGE no compartidos o raros y, al revés, cómo los nombres registrados en lengua española no compartidos o raros en la lengua portuguesa de Brasil serían evaluados por hablantes nativos de este idioma (ORTEGA-OJEDA, 1994).

Por fin, partiendo del principio de que la equivalencia y la divergencia son graduales, se han analizado los nombres según la relación existente entre ellos en términos de frecuencia: equivalencia total, cuando el mismo nombre es usado en una misma proporción en ambos países; equivalencia relativa, cuando el nombre existe en uno de los países pero posee frecuencia muy diferente en el otro (por ejemplo, es un nombre muy usado en España pero casi no es usado en Brasil) y no equivalencia, cuando en un país un nombre es muy usado en un país o es empleado de forma esporádica o rara o incluso no existe en otro.

En cualquier caso, una vez salvados estos pequeños escollos, los repertorios presentan una adaptabilidad más que suficiente para su contraste, objetivo último de esta investigación.

En lo que se refiere al análisis cualitativo, hemos cotejado los nombres de las listas con diversos catálogos de antropónimos, dando especial relevancia a los trabajos de Guérios (1972 y 1981), obras de referencia dentro de los estudios onomásticos. Asimismo, se han consultado los diccionarios de los nombres de pila de García Gallarín (1998) y Albaigès (1995), además de la consulta de diversas fuentes online. También han resultado de mucha ayuda las aplicaciones desarrolladas tanto por INE como IBGE, que permiten consultar el desarrollo de nombres concretos a lo largo de las diferentes décadas.

\section{ANÁLISIS DE RESULTADOS}

\subsection{ANÁLISIS GENERAL}

A continuación, nos detendremos en los rasgos definitorios de los dos corpus y los puntos en común entre ambos. En el cuadro 1 se detallan varios índices que nos permitirán caracterizarlos.

\begin{tabular}{|c|c|c|c|c|c|c|}
\hline & \multicolumn{3}{|c|}{ HOMBRES } & \multicolumn{3}{|c|}{ MUJERES } \\
\hline & & Brasil & España & & Brasil & España \\
\hline Número de nombres & & 180 & 180 & & 180 & 180 \\
\hline Nombres diferentes & & 53 & 49 & & 77 & 63 \\
\hline Índice de diversidad onomástica & & 0,29 & 0,27 & & 0,43 & 0,35 \\
\hline Nombres compartidos diferentes & 23 & $43,4 \%$ & $46,9 \%$ & 24 & $31,2 \%$ & $38,1 \%$ \\
\hline Índice de presencia & & $116(64,4 \%)$ & $127(70,6 \%)$ & & $83(46,1 \%)$ & $86(47,78 \%)$ \\
\hline
\end{tabular}

Fuente: las autoras 
Como hemos advertido en el apartado anterior, contamos con 720 nombres de los cuales 242 son diferentes: 102 nombres diferentes de hombres (53 en Brasil y 49 en España) y 140 nombres diferentes de mujeres (77 en Brasil y 63 en España). En general parece que la lista de nombres femeninos presenta más diversidad que la de los masculinos, dato que se ratifica con el índice de diversidad onomástica (ya empleado en Fernández Juncal 2002 y 2018). Este valor se halla dividiendo el número de nombres diferentes entre el total de nombres, de forma que alcanzaríamos el valor 1 si todas las personas tuvieran un nombre diferente y un valor cercano a 0 si todas las personas compartieran el mismo antropónimo.

Pues bien, tanto en el caso brasileño como en el caso español, son las mujeres las que poseen mayor variedad en su denominación. Estos datos refrendan lo que ya podemos considerar una constante en los estudios onomásticos (ROSSI, 1965, BOYD-BOWMAN 1970; ALLEN et al. apud LAWSON, 1971; LIEBERSON 2000; LÓPEZ FRANCO, 2014). Es evidente que hombres y mujeres poseen repertorios diferentes, con escasos puntos comunes (ALFORD 1988), y que esta distinción de sexos también se aplica a los animales (MORANT 2016), pero es también una constante que los hábitos onomásticos difieren en los mecanismos que rigen la elección de un nombre en función del sexo de la persona recién nacida. Como ya señalábamos en Fernández Juncal (2002, 2019, 2021), la dispersión de nombres femeninos es más acusada que la de los nombres masculinos. En el caso de estos últimos, son los que suelen cargar con la continuidad temporal de la familia por lo que suelen recibir nombres de herencia y, por lo tanto, más tradicionales. Las mujeres están menos afectadas por la transmisión familiar y su repertorio está mucho más abierto a innovaciones, frente al masculino, que suele ser más conservador. Lieberson y Bell (1992) señalan además que, como consecuencia de lo anterior, el repertorio masculino se mantiene más estable mientras que el femenino es más dinámico.

Los nombres de hombre muestran una línea más permanente, en gran parte por estar ligados a conceptos como la herencia, la continuidad, mientras que los nombres de mujer muestran más dinamismo y están más afectados por otro tipo de valores: la originalidad y la innovación. Esta tendencia, detectada hace más de 50 años, sigue siendo perceptible, también en diferentes culturas y sociedades, sobre todo en aquellas en que se percibe una trayectoria histórica de tipo patriarcal, como sucede con los países de la Europa mediterránea en general, donde se incluyen las culturas española y brasileña, y también en otras más alejadas como las sajonas estadounidense (LIEBERSON, 2000; GERRITZEN 2006).

Hemos adelantado en el cuadro 1 también los resultados acerca de las coincidencias entre ambos catálogos. En consonancia con lo expuesto en el párrafo anterior, el nivel de elementos compartidos entre los dos conjuntos de antropónimos es superior en el caso de los varones, lo que no ha de extrañar ya que estamos ante denominaciones que forman parte del acervo antroponímico de ambas naciones, cuyas lenguas son próximas y con tradición onomástica paralela. Esta tendencia se ratifica observando dos porcentajes: los nombres diferentes comunes y el índice de presencia, que definimos como el total de ocurrencias (también repetidas) dentro del total del corpus, incluyendo todos los nombres de todas las décadas. Este último valor es especialmente significativo, ya que nos acercamos al 50\% de casos para las mujeres y superamos ampliamente esa cifra en el caso de lo varones. Una vez más comprobamos la estabilidad del repertorio masculino y sus semejanzas dada la preservación de unidades con larga trayectoria, como comprobaremos con el análisis cualitativo.

Conviene ahora examinar cómo se ha producido la evolución de las series en los dos países partiendo de los elementos que comparten (cuadro 2 y gráfico 1).

Cuadro 2: Evolución de nombres compartidos y divergentes entre ambos repertorios

\begin{tabular}{c|c|c|c|c|c|c|c|c|c|c|c} 
& antes 30 & $\mathbf{3 0}$ & $\mathbf{4 0}$ & $\mathbf{5 0}$ & $\mathbf{6 0}$ & $\mathbf{7 0}$ & $\mathbf{8 0}$ & $\mathbf{9 0}$ & $\mathbf{2 0 0 0}$ & total \\
\hline HOMBRES & & & & & & & & & & & \\
\hline convergentes & 12 & 10 & 9 & 10 & 9 & 8 & 7 & 5 & 3 & & 11 \\
\hline divergentes & 8 & 10 & 11 & 10 & 11 & 12 & 13 & 15 & 17 & & 9
\end{tabular}




\begin{tabular}{|c|c|c|c|c|c|c|c|c|c|c|}
\hline \multicolumn{11}{|l|}{ MUJERES } \\
\hline convergentes & 11 & 10 & 8 & 8 & 5 & 4 & 5 & 3 & 4 & 4 \\
\hline divergentes & 9 & 10 & 12 & 12 & 15 & 16 & 15 & 17 & 16 & 16 \\
\hline & & & & & & & & & & \\
\hline
\end{tabular}

Gráfico 1: Evolución de nombres convergentes (\%) entre ambos repertorios

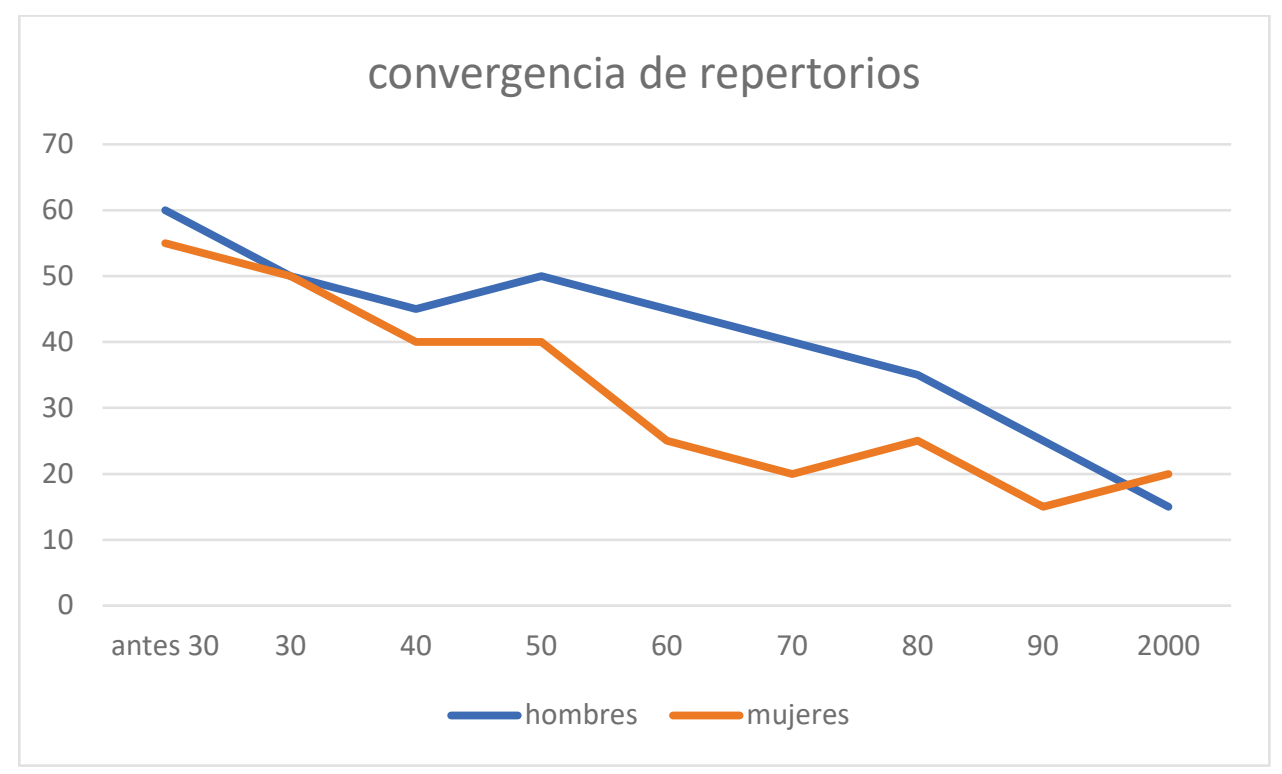

Fuente: las autoras

De acuerdo con la tabla 2 y el gráfico 1, los dos catálogos han ido distanciándose con el tiempo, de forma que, antes de los años 30 , eran más los nombres compartidos que los divergentes (el 60\% de los masculinos y el 50\% de los femeninos) hasta llegar a un grado de coincidencia muy limitado (el 15\% y el 20\% para hombres y mujeres respectivamente). Este es un proceso que también ha sido detectado por otras investigaciones socionomásticas (TWENGE et al., 2010). En España se ha producido una evolución desde una situación en que pocos nombres eran compartidos por muchas personas hasta una época de mucha mayor dispersión onomástica, en que priman otros valores a la hora de elegir un nombre, como la originalidad y el individualismo (FERNÁNDEZ JUNCAL, 2002, 2019; GARCÍA GALLARÍN, 2007). Es la misma situación que encuentran Xi et al. (2014) para los nombres más frecuentes de Estados Unidos a lo largo de 130 años: "The given names change from few take all to a more equally distributed way over time" (Xi et al. 2014,p. 141). Así, en ocasiones por la propia transformación del marco legal, se ha pasado de un repertorio relativamente reducido a uno que se renueva mediante la creación de nuevos componentes, mediante la recuperación de elementos perdidos o mediante la incorporación de unidades onomásticas de todo tipo de procedencias (GARCÍA GALLARÍN, 2007; FERNÁNDEZ JUNCAL, en prensa). De todas formas, no hay que perder de vista que, aunque los padres intentan encontrar nombres raros o únicos para sus hijos, sus preferencias parecen seguir, a pesar de todo, tendencias típicas del periodo (AINIALA; ÖSTMAN, 2017).

A partir de los años 70 observamos cambios sustanciales en el mundo que tienen consecuencias directas sobre los patrones onomásticos: de esa forma, en España se produce un cambio de régimen político, con su consiguiente proyección en la legislación; 
hay evidencias de una mayor apertura internacional, del aumento de la urbanización o de la ampliación del acceso a los medios de comunicación. Un proceso muy semejante se ha detectado en Brasil, donde Frai (2016) destaca también el papel decisivo de los medios de comunicación masivos ${ }^{3}$. En otros entornos, más o menos distantes, se manifiestan transformaciones semejantes: Jiménez Segura (2014) nos remite a los trabajos de Caffarelli (2004) y de Caffarelli y Gerritzen (2002) en diversos lugares del mundo (Italia, España, Japón, Países Bajos, etc.) que apuntan en una misma dirección: ha aumentado el repertorio de los nombres y su ciclo de atribución se ha acortado, lo que refleja la importancia que la moda va adquiriendo como factor decisivo en la selección de los nombres personales en esos territorios. Por ejemplo, Barucca et al. (2015) descubren en Estados Unidos un patrón onomástico estable que, de repente, experimenta cambios en las últimas décadas del siglo XX. Gerritzen (2006) y Mitzlaff y Stumme (2008) destacan asimismo el papel de la globalización y de empleo de Internet en la atribución de antropónimos y en la ampliación e intercambio de fuentes onomásticas.

En cualquier caso, podemos concluir que la transmisión de los nombres es un hábito en decadencia y ha dado paso a otros patrones onomásticos que se han visto influidos por diversas circunstancias. Resumimos los postulados de Lieberson (2000): en primer lugar, el aumento de la instrucción académica favorece la ruptura con prácticas cuyo único valor es el de ser tradicionales; en segundo lugar, la creciente urbanización de la sociedad y el mayor contacto con los medios de comunicación de masas mejora el conocimiento de nuevas formas de denominación. En tercer lugar, el modelo familiar ha cambiado sustancialmente en las últimas décadas y con ello todos los usos asociados a él. Finalmente, parece que se ha ido produciendo un cambio de valor de lo viejo o antiguo frente a la más elevada estimación de lo joven y lo nuevo. Esto hace que los padres actuales prefieran para sus hijos nombres que no remitan al pasado. Para ratificar esta tendencia aportamos en el cuadro 3 el dato relativo al número de nombres multigeneracionales, es decir, los antropónimos que aparecen en las listas de popularidad de más de cuatro generaciones y que deberíamos considerar como los nombres más patrimoniales de los dos repertorios. En el cuadro 4 precisamos los nombres más empleados a lo largo del periodo analizado.

\begin{tabular}{|c|c|c|c|c|c|}
\hline & & \multicolumn{2}{|c|}{ BRASIL } & \multicolumn{2}{|c|}{ ESPAÑA } \\
\hline & & HOMBRES & MUJERES & HOMBRES & MUJERES \\
\hline Nombres diferentes & & 53 & 77 & 49 & 63 \\
\hline \multicolumn{6}{|l|}{$\begin{array}{c}\text { Nombres } \\
\text { multigeneracionales }\end{array}$} \\
\hline & 9 generaciones & 4 & 2 & 2 & 1 \\
\hline & 8 generaciones & 2 & 0 & 1 & 0 \\
\hline & 7 generaciones & 3 & 0 & 2 & 1 \\
\hline & 6 generaciones & 0 & 2 & 4 & 1 \\
\hline & 5 generaciones & 5 & 2 & 7 & 9 \\
\hline & 4 generaciones & 4 & 5 & 8 & 9 \\
\hline & & $18(34 \%)$ & $11(14,3 \%)$ & $24(49 \%)$ & $21(33,3 \%)$ \\
\hline
\end{tabular}

Fuente: las autoras

${ }^{3}$ Vandebosch (1998) destaca el papel que desempeñan los medios de comunicación en la creación y propagación de modas onomásticas. 
Cuadro 4: Nombres más repetidos a lo largo del periodo estudiado

\begin{tabular}{c|c|c|c|c|c|c|c}
\multicolumn{7}{c}{ BRASIL } & \multicolumn{2}{c}{ ESPANA } & MOMBRES & & GEN. \\
\hline HOMBRES & & MUJERES & & GEN. & 9 \\
\hline Carlos & GEN & & GEN. & & 9 & María & 9 \\
\hline João & 9 & Maria & 9 & Manuel & 9 & María Carmen & 7 \\
\hline José & 9 & Antonia & 6 & Jesús & 8 & Carmen & 6 \\
\hline Paulo & 9 & Francisca & 6 & Francisco & 7 & Ana & 5 \\
\hline Antônio & 8 & Rita & 5 & Miguel & 7 & Ana María & 5 \\
\hline Francisco & 8 & Rosa & 5 & Carlos & 6 & Antonia & 5 \\
\hline Luis & 7 & Aparecida & 4 & José & 6 & Dolores & 5 \\
\hline Peraldo & 7 & Josefa & 4 & José Antonio & 6 & Francisca & 5 \\
\hline
\end{tabular}

Fuente: las autoras

Comprobamos que, en general, los antropónimos masculinos muestran mayor probabilidad de permanencia a lo largo del tiempo que los femeninos, rasgo que concuerda con las tendencias señaladas con anterioridad.

Los nombres multigeneracionales tienen más peso en el conjunto de nombres diferentes masculinos españoles (suponen casi la mitad de ellos). No obstante, hay cuatro nombres portugueses de varón (João, José, Paulo y Antônio) frente a solo dos españoles (Antonio y Manuel) que resisten mejor los cambios que se producen en el catálogo general. En el caso de los nombres femeninos, la nómina es más amplia y se observa mayor volatilidad en el caso de los nombres brasileños, más acusada si consideramos que en la lista española se repiten dos nombres en dos variantes (Carmen y María Carmen y Ana y Ana María).

Aceptando los numerosos puntos en común entre los patrones brasileño y español, percibimos también algunas discrepancias, no taxativas, pero sí de grado. Nos movemos, por lo tanto, entre dos tendencias: por una parte, la conservación de elementos patrimoniales (y esto ocurre sobre todo en los corpus masculinos y en el corpus español) y, por otra parte, la diversidad, la movilidad de los repertorios (y esto ocurre sobre todo en los corpus femeninos y en el corpus brasileño en general).

El cuadro 5 confirma estos extremos. En ella se aportan las medidas de centralidad y dispersión referentes al número de generaciones afectadas por la presencia de determinados nombres. Ratificamos que el promedio de generaciones de los nombres de la lista es relevante: de un máximo de 9 generaciones posibles (es decir, siempre se usarían los mismos nombres), el índice superior o cercano a 3 es notable. La moda, es decir, el número de generaciones de un nombre habitual es de 2 (3 para los antropónimos masculinos españoles), lo que indica una evolución del conjunto bastante dinámica, con cambios sustanciales de una generación a otra, pero también con unidades repetidas. En cuanto a la desviación, hay más diversidad en la extensión de generaciones en el empleo de los nombres de hombre mientras que las mujeres concentran su uso en menos espacio de tiempo. 
Cuadro 5: Medidas de centralidad y dispersión del número de generaciones de los diferentes nombres en los dos repertorios

HOMBRES
MUJERES

\begin{tabular}{|c|c|c|c|c|}
\hline & Brasil & España & Brasil & España \\
\hline Media & 3,4 & 3,7 & 2,4 & 2,9 \\
\hline Mediana & 3,0 & 3,5 & 2,0 & 2,0 \\
\hline Moda & 2,0 & 3,0 & 2,0 & 2,0 \\
\hline Desviación & 2,5 & 2,2 & 1,6 & 1,7 \\
\hline
\end{tabular}

Fuente: las autoras

\subsection{ANÁLISIS DETALLADO}

\subsubsection{Nombres totalmente convergentes}

La comparación de los antropónimos más usados en Brasil y en España ha revelado la existencia de nombres totalmente convergentes, esto es, un conjunto de nombres compartidos que están en ambos repertorios y son muy empleados en los dos países: 23 nombres en la antroponimia masculina y 24 nombres de la antroponimia femenina. Para una mejor caracterización de este conjunto de nombres, se hizo un análisis de su significado etimológico y del contexto histórico y cultural que probablemente propició la introducción y utilización de esos nombres en los idiomas español y portugués. Cuando los nombres son convergentes porque comparten un mismo étimo, aunque haya pequeñas diferencias gráficas, ambos nombres son asimilados. Estos datos se visualizan en el cuadro 6.

Cuadro 6: Nombres totalmente convergentes

\begin{tabular}{c|c} 
ANTROPONIMIA MASCULINA & ANTROPONIMIA FEMININA \\
\hline Alexandre - Alejandro & Ana \\
\hline André - Andrés & Antônia - Antonia \\
\hline Antônio - Antonio & Beatriz \\
\hline Carlos & Carla \\
\hline Daniel & Cláudia - Claudia \\
\hline Diego & Cristiane - Cristina
\end{tabular}




\begin{tabular}{|c|c|}
\hline Francisco & Francisca \\
\hline João - Juan & Helena - Elena \\
\hline Joaquim -Joaquín & Isabel/Isabela - Isabel \\
\hline Jorge & Joana- Juana \\
\hline José & Josefa \\
\hline Luis/Luiz - Luis & Júlia -Julia \\
\hline Manoel/Manuel - Manuel & Lúcia/Luzia - Lucía \\
\hline Marcos & Luiza- Luisa \\
\hline Mario & Maria- María \\
\hline Miguel & Natália- Natalia \\
\hline Paulo -Pablo & Patrícia - Patricia \\
\hline Pedro & Rosa \\
\hline Rafael & Sandra \\
\hline Sérgio - Sergio & Sara \\
\hline Vicente & Sônia - Sonia \\
\hline Vitor- Víctor & Tereza/Terezinha ${ }^{4}-$ Teresa \\
\hline & Vanessa - Vanesa \\
\hline
\end{tabular}

Fuente: las autoras

El análisis señala que el principal factor de convergencia antroponímica se relaciona con la religión católica, predominante en la Península Ibérica y en América Latina, y al cristianismo como un todo: 18 de los 47 prenombres repartidos (38\% de lo total) son nombres cristianos y/o católicos. Dentro de esta categoría, distinguimos los siguientes tipos de nombres: (1) nombres hebraicos, griegos o latinos con significado etimológico religioso; (2) nombres hebraicos que remiten a personajes del Antiguo o del Nuevo Testamento; (3) nombres relacionados con Jesucristo o su familia; (4) nombres relacionados con los apóstoles, y (5) nombres de santos de la Iglesia Católica (SEIDE, 2021).

En la primera categoría, destacamos dos nombres masculinos y dos nombres femeninos: Vicente; Vitor-Vitor; Cristiane-Cristina y Natália-Natalia ${ }^{5}$. Conforme a las informaciones recogidas en el diccionario etimológico de nombres y apellidos de Guérios, Vicente significa el 'vencedor do mal', es "de origem cristã", un nombre cognado de "v.vincere (...) relacionado ao prenome francês $r$. Vincent" (GUÉRIOS, 1981, p. 246). Vitor, a su vez, ya era, antes de la llegada del cristianismo, un nombre de buen augurio que fue reinterpretado de acuerdo con la ideología cristiana: "Entre os pagãos o nome Victor trazia a ideia de vitória militar, mas entre os cristãos dos primeiros séculos (vários os santos desse nome do século $3^{\circ}$ ao $6^{\circ}$ ) o seu uso aliava-se à ideia de vitória sobre o pecado"

\footnotetext{
${ }^{4}$ Considerando el criterio etimológico, son nombres equivalentes, sin embargo, en nombres que están en diminutivo, hubo cambio funcional de hipocorístico a nombre de pila o nombre civil.

${ }^{5}$ En estas parejas de nombres, el primero está en lengua portuguesa y el segundo en lengua española. Si solo se presenta un nombre, es que hay homografía de nombres, esto es, la misma forma gráfica es utilizada en los dos idiomas.
} 
(GUÉRIOS, 1981, p. 249). Los nombres femeninos, a su vez, presentan significado claramente religioso: el primero por significar 'aquella que es cristiana'6 (GUÉRIOS, 1981, p. 97) y el segundo por su significado de "nascida no Natal de Jesus Cristo” (GUÉRIOS, 1981, p. 148).

En la segunda categoría, hay cuatro nombres masculinos y uno femenino oriundos del Antiguo Testamento: Daniel (GUÉRIOS, 1981, p. 100), Joaquim-Joaquín, (GUÉRIOS, 1981, p. 151), Manuel (GUÉRIOS, 1981, p. 177), Rafael (GUÉRIOS, 1981, p. 209) y Sara (GUÉRIOS, 1981, p.221). En la tercera categoría nos encontramos con los nombres Maria-María, José-Jose y Josefa (GUÉRIOS, 1981, p. 152). En la cuarta, hallamos cuatro nombres de apóstoles y las formas femeninas de uno de ellos: João-Juan y Joana-Juana (GUÉRIOS, 1981, p. 151), Marcos (GUÉRIOS, 1981, p. 170), Paulo-Pablo (GUÉRIOS, 1981, p. 198) y Pedro (GUÉRIOS, 1981 , p. 199).

Por fin, en la última categoría, en la cual se evidencia más el catolicismo, están los nombres de santos, cuatro masculinos y algunas de las formas femeninas correspondientes: Antônio-Antonio y Antônia-Antonia (GUÉRIOS, 1981, p. 59), Francisco y Francisca (GUÉRIOS, 1981, p. 123), Jorge (GUÉRIOS, 1981, p. 152) Luiz/Luis-Luis y Luiza. De acuerdo con Gúerios, el nombre Luiz proviene del nombre francés Louis, el cual se "tornou popular por São Luis, rei de França e, nos tempos modernos, S. Luís de Gonzaga" (GUÉRIOS, 1981, p. 165). Hay también nombres de santas, a saber, Ana (GUÉRIOS, 1981, p. 249), Rosa, el cual fue "difundido graças a Santa Rosa de Viterbo (se. 13) e a Sta. Rosa de Lima (1586-1617)” (GUÉRIOS, 1981, p. 214.), y Teresa-Terezinha, sobre el cual informa Guérios que "aparece, pela primeira vez, na Espanha (...) o nome se tornou popular desde Santa Teresa de Jesus (século XVI) e, atualmente, por Santa Teresinha do Menino Jesus (1873-1897) -Diminutivo. Hipocorístico” (GUÉRIOS, 1981, p. 236).

Otro factor de convergencia son los nombres de origen latino que pueden haber sido incorporados a los repertorios antroponímicos de la Península Ibérica en la época del Imperio Romano. Pertenecen a esta categoría dos nombres masculinos y cinco nombres femeninos, siendo uno de ellos la forma femenina de uno de los nombres masculinos: Carlos y Carla, "um dos pouquíssimos nomes gen. antigos de um só tema” (GUÉRIOS, 1981, p. 86), Sérgio-Sergio (GUÉRIOS, 1981, p. 225), Cláudia-Claudia (GUÉRIOS, 1981, p. 93), Júlia-Julia (GUÉRIOS, 1981, p. 153), Lúcia-Lucía (GUÉRIOS, 1981, p. 165) y Patrícia-Patricia (GUÉRIOS, 1981, p. 197).

Hay también en común algunos nombres de origen griego, probablemente introducidos a través de la lengua latina, dada la influencia de la cultura helena en el Imperio Romano. En esta categoría hay dos nombres masculinos y dos nombres femeninos: Alexandre ${ }^{7}$-Alejandro (GUÉRIOS, 1981, p. 52), André-Andrés, Andrea/Andreia-Andrea (GUÉRIOS, 1981, p. 57) y Helena-Elena (GUÉRIOS, 1981, p. 140). Encontramos también Mário-Mario, de origen etrusco (GUÉRIOS, 1981, p. 172), que remite a los pueblos prerromanos con los cuales los habitantes de la Península Ibérica establecieron comercio antes de la colonización romana de la región.

En la antroponimia masculina brasileña hay dos nombres cuyo étimo es español y cuya existencia en el repertorio brasileño puede explicarse sea por la historia medieval que Portugal y España comparten, sea por la influencia española en Brasil en el siglo XVII: Diego, "Forma espanhola de Diogo" (GUÉRIOS, 1981, p. 102) y Fernando (GUÉRIOS, 1981, p. 119).

Solamente en la antroponimia femenina hay nombres compartidos de orígenes diversos. Hay dos de origen itálico - probablemente incorporados por influencia del Renascimiento: Beatriz (GUÉRIOS, 1981, p. 70) y Sandra, una "abreviação italiana. de Cassandra, ou Alessandra, v. Alexandre" (GUÉRIOS, 1981, p.221). Hay un nombre cuyo étimo apunta a un origen mediterráneo incierto en común, el nombre Isabel/Isabela-Isabel. Según Guérios, es un nombre portugués y español proveniente del nombre Elisabete, equivalente a los nombres Isabela y Elisabel en el portugués arcaico, Isabella en la lengua española e Isabelle en la lengua francesa (GUÉRIOS, 1981, p. 147).

\footnotetext{
${ }^{6}$ Se observa que el nombre en lengua portuguesa presenta el morfema - $e$ mientras que en la lengua española el morfema de género es - $a$, diferencia que retomaremos a lo largo de este artículo.

${ }^{7}$ Como en Cristiane, aparece el morfema -e en este nombre, también por influjo del francés, según Guérios.
} 
Hallamos, por fin, dos nombres cuyos orígenes no son ni portugués, ni español, ni italiano: Sônia-Sonia, de étimo ruso (GUÉRIOS, 1972, p.201) y Vanessa-Vanesa, que es un "Nome criado pelo escritor americano Dean Swift”, (GUÉRIOS, 1972, p.212).

\subsubsection{Prenombres relativamente convergentes}

El número de nombres que no son totalmente convergentes es superior al de los que lo son. En la antroponimia española masculina hay 18 nombres y en la femenina, 32 nombres. En la antroponimia brasileña masculina, a su vez, se detectan 28 nombres no compartidos y en la antroponimia femenina, 48. El hecho de que estos nombres no están listados como los más usados en el período abarcado en ambos países no implica que todos ellos estén ausentes en el repertorio antroponímico brasileño o en el repertorio antroponímico español, sino que son usados con frecuencia distinta, tal como se evidencia en las subsecciones siguientes.

a. Análisis de los nombres usados en España relativamente convergentes desde la perspectiva de la antroponimia brasileña

Con el objeto de saber de qué manera los nombres del repertorio español que no son totalmente convergentes con los del repertorio brasileño se llevó a cabo un análisis cuantitativo por el cual se descubrió qué nombres españoles son poco frecuentes y cuáles son inexistentes desde el punto de vista de la antroponimia brasileña. Para cada nombre de la antroponimia española no compartida con la antroponimia brasileña, se consultó en el IBGE la información relativa a la frecuencia porcentual respecto al número de habitantes. Estos números fueron evaluados según parámetros distintos porque se consideró el hecho de que los nombres femeninos son más diversificados que los masculinos. Como se sabe y se señaló en el inicio de este artículo, la antroponimia femenina es más dinámica, presenta mayor índice de diversidad léxica y es más volátil.

Para la antroponimia masculina, fueron evaluados como nombres muy raros los que tenían porcentajes desde el 0,01\% hasta el $0,03 \%$, poco usados o frecuentes por una o dos décadas los que presentaban porcentajes por encima del 0,3\% hasta el 0,07\%, y todos aquellos cuyo porcentual era igual o mayor que 0,08\% fueron valorados como nombres normalmente usados en Brasil. Los resultados se visualizan en el cuadro 7.

Cuadro 7: Nombres masculinos normalmente usados en España y su uso en Brasil

\begin{tabular}{c|c|c} 
Normalmente usados en Brasil & Poco usados en Brasil & Raros en Brasil \\
\hline Enrique & Alberto & Javier \\
\hline Iván & Álvaro & Óscar \\
\hline Julián & Cristian & Raúl \\
\hline Adrián & Hugo & Ramón \\
\hline David & & Emilio \\
\hline Félix & & Ángel \\
\hline & & Rubén
\end{tabular}

Fuente: las autoras

Del conjunto de nombres habitualmente usados en España, son extremadamente raros en Brasil los nombres españoles Javier (y también su correlato portugués Xavier), Jesús, Oscar, Raúl, Ramón, Emilio, Ángel, Julián y Adrián. Estos nombres, son probablemente vistos como poco brasileños o, incluso, extranjeros. 
Con relación a los nombres Julián y Adrián, hay que subrayar que existen los nombres Adriano y Juliano ${ }^{8}$, cuyos porcentajes de uso indican que ambos son considerados, por los brasileños, como normales. En este caso, desde la perspectiva de la lengua portuguesa de Brasil, mientras Adriano y Juliano son vistos como nombres brasileños, los nombres Julián y Adrián, que están registrados en IBGE, son, probablemente vistos como nombres no brasileños. Esta distinción también ocurre con David-Davi, y HenriqueEnrique, cuyas grafías en lengua española son raramente usadas. En la clasificación intermedia, esto es, de los nombres pocos usados, pero que no son raros, hallamos los nombres Alberto, Álvaro, Hugo e Iván. Es interesante notar que, mientras Ángel es raramente usado, su correlato Ângelo está en esta categoría intermedia. Lo mismo ocurre con los nombres Cristián, poco usado, y Cristiano, normalmente usado. En lo que concierne el nombre Gerardo, este nombre es tan usado en España como lo es su equivalente en portugués Geraldo. Sin embargo, el empleo de la forma en la lengua española en Brasil es extremamente raro, pues es inferior a $0,01 \%$ por millón de habitantes.

Con relación a los nombres femeninos, los parámetros para que el nombre fuese considerado raro fueron ajustados, teniendo en cuenta que es un hecho reconocido en Socionomástica que se percibe más diversidad léxica en la antroponimia femenina (vid. apartado 3.1). Se consideraron raros los nombres inferiores al 0,02\% de aparición; se evaluaron como poco usados o frecuentes por una o dos décadas los nombres con frecuencia relativa desde el 0,03\% hasta el 0,07\%, y nombres normalmente usados en Brasil los que presentan porcentaje superior al $0,07 \%$.

Hay que aclarar que fueron sumados los porcentajes de las variantes gráficas teniendo en cuenta que estas variantes suelen ser elegidas por razones estéticas. De este conjunto de nombres, 12 son usados normalmente, 6 son poco usados y los demás son raramente usados. Estos resultados se visualizan en el cuadro 8.

Cuadro 8: Nombres femeninos normalmente usados en España y su uso en Brasil

\begin{tabular}{c|c|c}
$\begin{array}{c}\text { Nombres femeninos normalmente } \\
\text { usados }\end{array}$ & Nombres femeninos poco usados & $\begin{array}{c}\text { Nombres femeninos raros en } \\
\text { Brasil }\end{array}$ \\
\hline Eva María (en IBGE Eva) & Carmen/Ma Carmen & María Ángeles \\
\hline Irene & Concepción & Dolores/María Dolores \\
\hline Laura & Lorena & María Jesús \\
\hline Marina & Manuela & María Mar Jó \\
\hline Marta & Susana & María Pilar/Pilar \\
\hline Mirian & Yolanda & Alba \\
\hline Mónica & & Encarnación \\
\hline Silvia & & Nerea \\
\hline Safía & & Noelia \\
\hline
\end{tabular}

${ }^{8}$ En estos casos, aunque comparten la etimología en común, son nombres distintos pues hay nombres brasileños en que el sufijo -ano cambia formalmente el nombre por lo que son evaluados como siendo nombres diferentes por los hablantes nativos. 


\begin{tabular}{l|c|c} 
Verónica & & Rocío \\
\hline & & Montserrat \\
\hline & & Mercedes
\end{tabular}

Fuente: las autoras

Los nombres Carmem, Conceição, Lorena y Manoela son poco usados o adoptados puntualmente por modas pasajeras. Finalmente, los nombres Eva, Irene, Laura, Marina, Marta, Miriam, Mônica, Paula, Raquel, Silvia, Sofia, Suzana y Verônica son normalmente usados.

b. Análisis de los nombres usados en Brasil relativamente convergentes desde la perspectiva de la antroponimia española

Para hacer posible la comparación entre los datos disponibles en INE y los datos de IBGE se adoptaron los siguientes procedimientos: se consideró la población española contabilizada en julio de 2017 y, tomando como referencia los números de frecuencia del INE, se hizo el cálculo de frecuencia de uso por millón de habitantes. Después se aplicaron los parámetros usados para el análisis de los datos del IBGE.

Para la antroponimia masculina fue necesario hacer un ajuste paramétrico para distinguir entre nombres poco usados o usados puntualmente por cuestiones de tendencias esporádicas y los que son normalmente usados. Se consideraron como raros los nombres cuya proporción por millón de habitantes es inferior al 0,04\% (frecuencias desde 465 hasta 1395); son poco usados o usados puntualmente los que presentan porcentajes oscilan desde el $0,04 \%$ a $0,18 \%$ (frecuencias de 1860 a 8754 ), y se valoran como normalmente usados los nombres con presencia mayor que $0,18 \%$ (frecuencias superiores a 8754). En el cuadro 9 se visualizan los nombres normalmente usados en Brasil y su uso en España: una mayoría, dieciséis nombres, son también normalmente usados y siete son poco o puntualmente (una o dos décadas por modismo) empleados en España.

Cuadro 9: Nombres masculinos normalmente usados en Brasil y su uso en España

\begin{tabular}{c|c} 
Normalmente usados en España & Poco o puntualmente usados en España \\
\hline Bruno & Fábio (en español Fabio) \\
\hline Claudio & Leandro \\
\hline Eduardo & Marcelo \\
\hline Felipe & Raimo \\
\hline Gabriel & Tiago (en español suele usarse Thiago $)$ \\
\hline Geraldo (en español Gerardo) & \\
\hline Guilherme (en español Guillermo) & \\
\hline Gustavo & \\
\hline Leonardo & \\
\hline Lucas & \\
\hline Nelson & \\
\hline
\end{tabular}




\begin{tabular}{c|c} 
Ricardo & \\
\hline Roberto & \\
\hline Rodrigo & \\
\hline Sebastião (en español Sebastián) &
\end{tabular}

Fuente: las autoras

En la antroponimia femenina, se usaron los mismos parámetros utilizados para el análisis de los datos de IBGE: son nombres raros los presentes hasta un 0,02\% (frecuencia hasta 930); nombres poco usados o usados puntualmente, aquellos con porcentajes desde más de un $0,02 \%$ hasta el 0,07\% (frecuencias desde 1869 hasta 3255) y nombres usados normalmente los que traspasan ese límite. Encontramos 23 nombres normalmente usados en los dos países, pero otros 11 nombres son poco o puntualmente usados en España.

Cuadro 10: Nombres femeninos más usados en Brasil y su uso en España

\begin{tabular}{|c|c|}
\hline Normalmente usados en España & Poco o puntualmente usados en España \\
\hline Adriana & Bianca \\
\hline Alessandra (Alejandra en español) & Bruna \\
\hline Alice (Alicia en español) & Eduarda \\
\hline Amanda & Fabiana \\
\hline Camila & Luciana \\
\hline Daniela & Marlene \\
\hline Elza (Elsa en español) & Nair (em español Naira) \\
\hline Fátima & Raimunda \\
\hline Fernanda & Renata \\
\hline Gabriela & Silvana \\
\hline Jéssica & Simone (en español Simona) \\
\hline \multicolumn{2}{|l|}{ Juliana } \\
\hline \multicolumn{2}{|l|}{ Larissa } \\
\hline \multicolumn{2}{|l|}{ Letícia (Leticia en español) } \\
\hline \multicolumn{2}{|l|}{ Mariana } \\
\hline \multicolumn{2}{|l|}{ Rafaela } \\
\hline \multicolumn{2}{|l|}{ Regina } \\
\hline Rita & \\
\hline
\end{tabular}




\begin{tabular}{c|c} 
Sebastiana & \\
\hline Tânia (Tania en español) & \\
\hline Tatiane & \\
\hline Vera & \\
\hline Vitória (Victoria en español) & \\
\hline
\end{tabular}

Fuente: las autoras

\subsubsection{Nombres raros desde la perspectiva de la antroponimia brasileña y desde la perspectiva de la antroponimia española}

Esta sección del artículo se centra en los nombres que, de hecho, no existen o son extremamente raros en uno de los repertorios. Con relación a los nombres considerados raros desde la perspectiva de la lengua portuguesa de Brasil y desde la perspectiva de la lengua española, se hizo un análisis más detallado para la verificación de los factores de divergencia.

Los nombres que se visualizan en el cuadro 11 son los más divergentes cuando se comparan el catálogo español con el brasileño; se trata de los nombres que más probablemente serían evaluados por los hablantes nativos de la lengua portuguesa de Brasil como no brasileños o poco típicos de Brasil.

Cuadro 11: Nombres más usados en España y raros en Brasil

\begin{tabular}{|c|c|}
\hline Antroponimia masculina & Antroponimia femenina \\
\hline Adrián & Alba \\
\hline Ángel & Dolores \\
\hline Emilio & Encarnación \\
\hline Félix & Mar \\
\hline Javier & Pilar \\
\hline Jesús & Mercedes \\
\hline Julián & Montserrat \\
\hline Óscar & Nerea \\
\hline Ramón & Noelia \\
\hline Raúl & Rocío \\
\hline Rubén (Rubem en portugués) & Rosario (Rosário en portugués) \\
\hline
\end{tabular}

Son raros en la antroponimia brasileña los nombres femeninos Alba, Encarnação, Nerea, Noelia, Rosario y Rocío. Acerca de los nombres Alba, Mary Montserrat, se nota que son, originalmente, un sustantivo común y un nombre de lugar y que hubo un proceso 
de recategorización. (LÓPEZ-FRANCO, 2020). Hay registros de estos nombres en Brasil, pero son rarísimos: durante todo el período que el IBGE abarca hubo solamente 263 personas llamadas Mar y 58 llamadas Montserrat.

En el caso de los nombres divergentes femeninos, desde el punto de vista de la antroponomástica brasileña es evidente la influencia de las advocaciones marianas. Muchos de los nombres raros españoles son advocaciones de la virgen, que están ligadas, que hacen referencia a un lugar concreto (Pilar, Rocío, Montserrat). También es algo particular la combinación del nombre María con nombre de varón en dos casos ( $M^{a}$ José y $M^{a}$ Jesús). Es curioso que existe la misma combinación inversa para hombres con María pospuesto (José María, Jesús María, Antonio María, etc.). En todos estos casos, son nombres compuestos que no son contabilizados por el IBGE que sólo incluye los nombres simples. Por esta razón no fue posible obtener datos sobre los nombres María Ángeles, María Carmen, María Dolores, María Jesús, María José, María Mar y María Pilar. Para estos, como ya hemos avisado, se buscó el porcentaje de uso del segundo nombre de los compuestos. Este procedimiento, claro está, no se pudo aplicar a los nombres de María José y Ma Jesús.

Respecto a los nombres masculinos, hecha excepción de los nombres Óscar, cuyo étimo es anglosajón (GÚÉRIOS, 1981, p.191), Raúl, cuyo étimo es germánico y la forma gráfica proviene de un nombre en lengua francesa (GUÉRIOS, 1981, p.210), y Rubén, cuyo origen es hebraico (GUÉRIOS, 1981,p.126), los demás presentan étimo latino o son nombres relacionados con el catolicismo.

En lo que se refiere a los antropónimos Adrián, Ángel y Julián, son formas poco usadas en Brasil, pero más frecuentes en su versión portuguesa: Ângelo, Adriano y Juliano. En estos casos la divergencia gráfica y fonética entre los nombres españoles y brasileños hace que sean evaluados cómo nombres distintos por los hablantes nativos de la lengua portuguesa de Brasil.

Con relación al nombre Javier, tanto la forma españolizada como la forma catalana Xavier "apellido de São Francisco de Xavier" (GUÉRIOS, 1981, p.253) son raras en Brasil. Respecto al nombre Ramón, la forma en español es rara en Brasil, pero no la versión portuguesa de este nombre, Raimundo (GUÉRIOS, 1981, p.209). En este caso, es evidente que la divergencia formal impide que los hablantes nativos relacionen estos nombres entre sí; solamente especialistas en historia de las lenguas o lectores de diccionarios etimológicos sabrían que Ramón es la forma catalana de Raimundo. En la lengua española ocurre el mismo fenómeno: estos nombres son evaluados como diferentes.

Con excepción de Jesús, los demás nombres forman parte del repertorio de nombres de la lengua portuguesa, pero en Brasil no son más usados. En el caso concreto del nombre Jesús, pensamos que su ausencia en el uso en Brasil está relacionada con un tabú de cuño religioso, por el cual no estaría permitido nombrar a alguien con el nombre de la divinidad.

A continuación, utilizando los datos del INE y tomando como base la frecuencia por millón de habitantes, se hace el camino inverso, esto es, verificar qué nombres serían vistos por los españoles como no españoles o poco típicos de España. Los nombres que así serían juzgados se visualizan en el cuadro 12.

Cuadro 12: Nombres más usados en Brasil y raros en España

\begin{tabular}{c|c} 
Antroponimia masculina & Antroponimia femenina \\
\hline Anderson & Aline \\
\hline Benedito $^{+\theta}$ & Alzira \\
\hline Edson & Aparecida \\
\hline Márcio & Benedita
\end{tabular}

\footnotetext{
${ }^{9}$ El nombre original es un topónimo vasco, Xabier, nombre del castillo donde nació este personaje. Esta grafía es la que se mantiene en la variante original vasca.

${ }^{10}$ El nombre equivalente Benito es el no.142 en orden de frecuencia en España.
} 


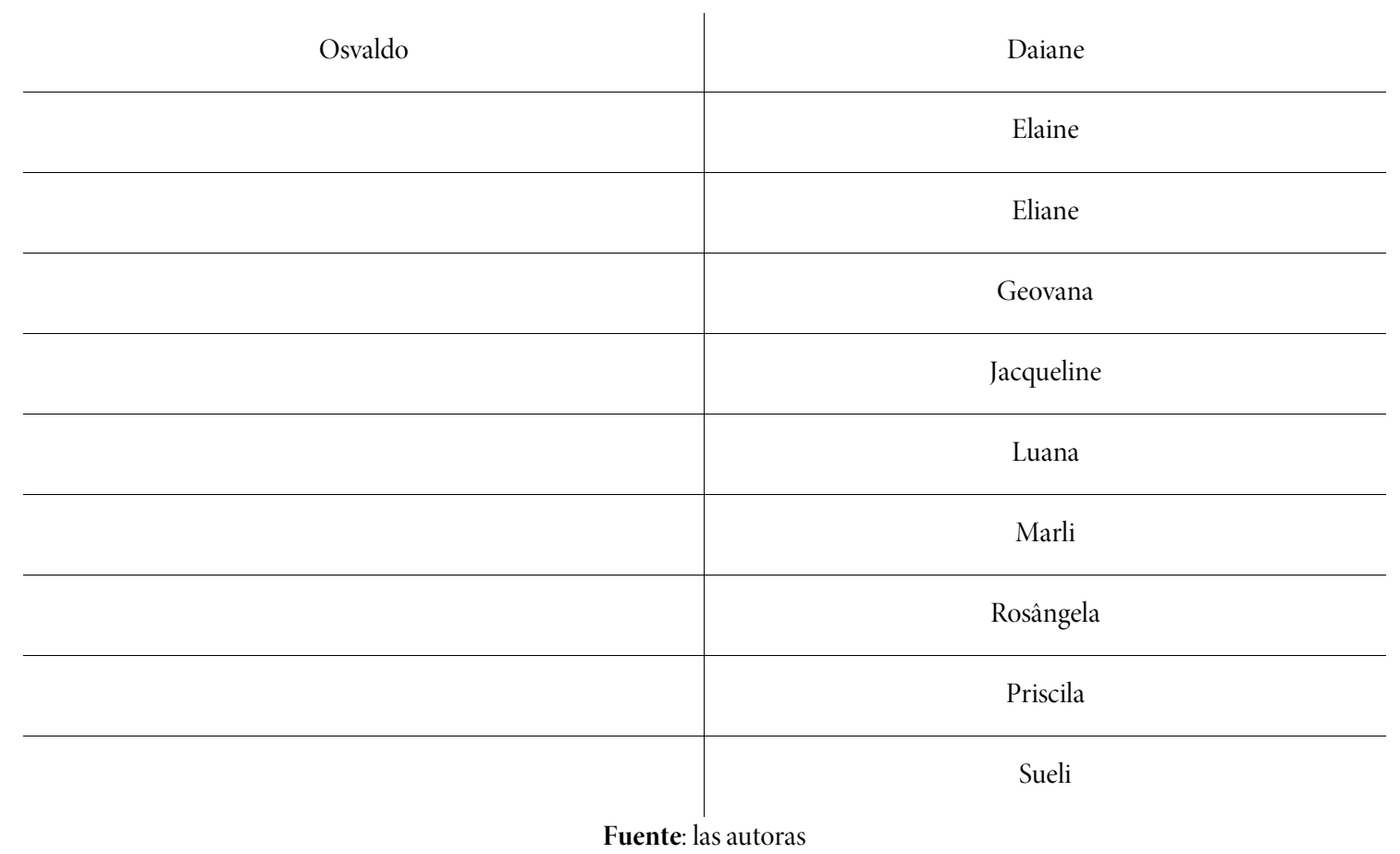

Es preciso aclarar que el nombre Benedito es de étimo latino y significado cristiano (GUÉRIOS, 1981, p.71), equivalente al nombre Benedicto/Benito en español. Mientras la forma portuguesa del nombre es rara, la segunda forma española no lo es. No obstante, la divergencia entre las formas impide que sean vistas como equivalentes por los hablantes nativos de la lengua española.

También provoca sorpresa la predilección por nombres con la terminación -son de los nombres Anderson, proveniente de un apellido germánico (GUÉRIOS, 1981, p.57), y Edson, proveniente del apellido inglés Edson. Los dos nombres son antiguos patronímicos en sus idiomas de origen; por lo tanto, en la lengua portuguesa de Brasil se produjo un proceso de cambio intracategorial (LOPÉZ-FRANCO, 2020). De acuerdo con Simões Neto y Soledade, nombres con esta terminación tienen por orígenes la lengua inglesa y las lenguas nórdicas (en las cuales también se utiliza la terminación -sen). En estos idiomas, el formante sigue existiendo en los apellidos, sin embargo, sin el sentido original de 'hijo de' (SIMÕES NETO; SOLEDADE, 2018, p.1311). En la lengua portuguesa de Brasil, el uso de apellidos ingleses como nombres de pila provocó el cambio categorial de apellido a nombre. Incluso, los nombres Wilson y Nelson, están registrados en listas de registro de parroquias del interior del estado de Río de Janeiro ya en 1928 (SIMÕES NETO ; SOLEDADE, 2018, p.1311).

Con respecto a los nombres terminados en -aldo, su origen es germánico (GUÉRIOS, 1981, p.130, p.192). El uso de nombres con esta terminación en Brasil es herencia de los colonizadores portugueses y remite a la historia medieval de la región ibérica, cuando los visigodos empezaron a habitar la región y se llevó a cabo la germanización de la antroponimia, que se pasó "na Idade Média em todas as regiões do antigo Império romano que foram sujeitas às grandes invasões e onde se constituíam reinos germânicos de maior ou menor estabilidade: Gália, Itália e Hispânia” (PIEL, 1989, p.130).

En lo que concierne a la antroponimia femenina percibida como rara desde la perspectiva española, hay que destacar la popularidad en Brasil del nombre Aparecida. Esta predilección está relacionada con el hecho de que Nossa Senhora Aparecida es la patrona de Brasil y el nombre originalmente formaba parte del nombre compuesto Maria Aparecida. Benedita y Priscila también son nombres relacionados con la religión: el primero es la forma femenina de Benedito, que ya hemos mencionado, y el segundo, de origen latino, es el diminutivo de "Prisca -Sta. Esposa de Áquila Atos dos Apóstolos e Timoteo e Santa virgem romana, sec. I" (GUÉRIOS, 1981, p. 205).

Aparece también el nombre Alzira, de probable origen germánico o árabe (GUÉRIOS, 1981, p.55), el nombre Sueli, de origen germánico, y el nombre Geovana, cuya grafía remite al nombre italiano Giovanna (DE FELICE, 1986, p.192). Mientras los dos 
primeros nombres podrían relacionarse con la historia de la antigua Hispania, la popularidad del tercero puede ser explicada por la influencia de la cultura y de la lengua italianas en Brasil, teniendo en cuenta la inmigración masiva de italianos en el país en el siglo XIX.

Confirmando que la antroponimia femenina brasileña está muy abierta a distintas influencias, en este conjunto hay nombres de origen francés. Aline es hipocorístico del nombre francés Adeline (GUÉRIOS, 1981, p.53); Eliane también es un nombre francés (GUÉRIOS, 1981, p. 109); Daiane es una variante gráfica brasileña del nombre francés Diane, y Jacqueline es la forma femenina del nombre francés Jacques. Respecto a la terminación -e del nombre Simone, y de muchos otros que la tienen, también está relacionada con la influencia de la lengua francesa en los nombres femeninos usados en Brasil (SOLEDADE, 2021, p.330).

Otro origen de los nombres de ese conjunto es la antroponimia ficcional en lengua inglesa: Elaine proviene del personaje "de Idylls of the King 1859 de Tennyson, poeta inglês” (GUÉRIOS 1981, p. 108). Finalmente, Rosângela es el resultado de la combinación de los nombres Rosa y Ângela (GUÉRIOS, 1981, p. 215).

\section{CONCLUSIONES}

Tanto el análisis cuantitativo como el examen detallado de los elementos del corpus analizado nos conducen en una misma dirección: los resultados de investigación presentados muestran que hay pocos nombres totalmente divergentes en los repertorios. Sin embargo, sería preciso entrevistar a hablantes nativos de los idiomas involucrados para saber si ellos evaluarían esos nombres de la misma manera en que se hace en este artículo, basado en datos estadísticos.

Si bien se trata de objetos de estudio diferentes, Seide y Frai (2019) llegaron a conclusiones semejantes en su investigación sobre el comportamiento de un mismo conjunto de nombres innovadores en Brasil y en España, también utilizando los datos del INE y del IBGE. En ese trabajo, también se detectó más convergencia en la antroponimia masculina en comparación con la femenina y, además, la hipótesis inicial de su investigación fue confirmada: en lo que respecta a la antroponimia masculina, había más similitud entre España y Brasil de lo que se confirmó en una investigación anterior contrastiva entre las antroponimias masculinas de Lituania y de Brasil que son países con lenguas y culturas muy lejanas entre sí (SEIDE; PETRULIONĖ, 2018). Tanto esas investigaciones como la presente corroboran que, cuando se observa más cercanía lingüística y cultural entre los países cuyos usos antroponímicos se comparan, más convergencia onomástica se ratifica.

No ha de extrañarnos esta convergencia antroponímica ya que la investigación se lleva a cabo en dos lenguas muy próximas cuyo desarrollo histórico y cultural ha ido en paralelo durante muchos siglos y que han compartido un entorno semejante en la evolución del mundo actual (urbanización, presencia de medios de comunicación, globalización). Sin embargo, debemos también considerar que estamos ante variedades lingüísticas de lenguas con rasgos propios, muy destacadamente para lo que nos interesa, desde el punto de vista fonético y desde la perspectiva ortográfica. Pero, sobre todo, nos encontramos con dos áreas geográficas que han sufrido avatares diferentes en este siglo y en el anterior. A este respecto, este estudio concluye que el corpus de Brasil es más dinámico y cambiante que el español, que este último conserva con más intensidad nombres patrimoniales entre los más empleados, mientras que el brasileño incorpora, principalmente en la antroponimia femenina, entre los más empleados y con más facilidad, unidades de otras lenguas.

Por lo tanto, nos planteamos también la pregunta: ¿nos encontramos ante fenómenos comunes que se repiten de manera similar en otras sociedades? Los estudios socionomásticos longitudinales permiten detectar tendencias comunes a sistemas con base lingüística diversa y partiendo de inventarios antroponímicos dispares. Parece que es ahora la coyuntura en que empiezan a percibirse con más nitidez los efectos de la globalización (GERRITZEN 2006), tanto en lo que tiene que ver con los movimientos demográficos a nivel mundial como en la universalización de la información a través de los medios de comunicación masivos.

Sin embargo, si nos atenemos a estudios contrastivos previos, como el de Seide y Petrulioné (2018) acerca de los antropónimos masculinos brasileños y lituanos, encontramos que, aunque la globalización pueda desempeñar un papel notable en la homogenización de repertorios, hay mucha más proximidad y los parecidos son sobresalientes entre los que presentan una clara 
proximidad histórica, cultural y, claro está, lingüística. Esta cercanía explica por qué en nuestra investigación hallamos muchos elementos compartidos de origen religioso, del catolicismo en particular. Este hecho nos retrotrae a la que quizás podamos considerar una de las etapas premonitorias de la globalización: la colonización de las Américas a través de acciones como la evangelización y la instalación de las misiones.

No obstante, son muchas las investigaciones que también perciben diferencias reseñables entre los corpus de hombres y mujeres en muy diferentes contextos geográficos: en nuestro caso se confirman algunos extremos que vienen avalados por estudios previos. Los repertorios de antropónimos masculinos son más estables, reflejan usos conservadores, mientras que los femeninos son más volubles y están más afectados por valores como la innovación y la originalidad, de forma que las discrepancias entre el corpus español y el brasileño se producen de manera más destacada en esa sección de los catálogos.

Finalmente, también concluimos que la Antroponomástica Comparada nos ofrece instrumentos para poder ver trayectorias convergentes y divergentes en variedades lingüísticas y en sintopías dispares, permitiendo una visión de conjunto de lo que también tienen en común.

\section{REFERENCIAS}

AINIALA, T.; ÖSTMAN, J.O. Introduction: socio-onomastics and pragmatics. In: AINIALA, T.; ÖSTMAN, J.O. (ed.). Socioonomastics. Amsterdam / Philadelphia: John Benjamins, 2017. p. 1-18.

ALBAIGÈS, J. M. Enciclopedia de los nombres propios. Barcelona: Ed. Planeta, 1995.

ALFORD, R.D. Naming and identity. A cross-cultural study of personal naming practices. New York: Harper \& Row, 1988.

AMARAL, E. T. R.; SEIDE, M. S. Nomes próprios de pessoa: introdução à antroponimia brasileira. São Paulo: Blucher, 2020.

BARUCCA P. et al. Cross-correlations of American baby names. Proceedings of the National Academy of Sciences, v.112, n.26, p. 7943-7947, 2015.

BOYD-BOWMAN, P. Los nombres de pila en México desde 1540 hasta 1950. Nueva Revista de Filología Hispánica, n. 19, p. 12-48, 1970.

CAFFARELLI, E. Frequenze onomastiche: I prenomi in Italia nel XX secolo" Rivista Italiana di Onomastica, v.VII, n.1, p. 291-354. 2004.

CAFFARELLI, E.; GERRITZEN, D. I prenomi più frequenti nel mondo alla fine del secondo millennio. Rivista Italiana di Onomastica, v.VIII, n.2, p. 631-709. 2002.

DE FELICE, E. Dizionario dei nomi italiani. Milano: Arnoldo Mondadori Editore, 1986.

FERNÁNDEZ JUNCAL, C. Algunos datos socionomásticos de una comunidad de la región funcional de Salamanca. In: BARTOL, J. A. et al. Nuevas aportaciones al estudio de la lengua española. Investigaciones filológicas. Salamanca: Luso-Española de Ediciones, 2002. p. 257-264.

FERNÁNDEZ JUNCAL, C. Evolution of Anthroponyms in an Area of Linguistic Transition: a Socio-Onomastic Study. Names: A Journal of Onomastics, v.66, n. 2, p. 85-95. 2018. 
FERNÁNDEZ JUNCAL, C. Evolución de los usos antroponímicos en español. Moenia, 25, p. 149-177. 2019.

FERNÁNDEZ JUNCAL, C. Estructura formal del repertorio antroponímico español. Revista de Filología Española, v.101, n.1., 2021 p.127-149.Disponible en https://doi.org/10.3989/rfe.2021.005. Acceso en: 18 ago. 20 .

FERNÁNDEZ JUNCAL, C. Permanencia, innovación y obsolescencia en el repertorio antroponímico español. Onomazéin. (en prensa).

FERNÁNDEZ JUNCAL, C.; HERNÁNDEZ MUÑOZ, Natividad. Disponibilidad léxica y socionomástica. OGIGIA, n. 25 , p. 185 210,2019

FRAI, P. H. Sócio-onomástica: Uma nova abordagem metodológica. Entreletras, v. 7, n.1, p. 91-106, 2016.

GARCÍA GALLARÍN, C. Los nombres de pila españoles. Madrid, Ediciones del Prado. 1998.

GARCÍA GALLARÍN, C. Tradición e innovación antroponímicas (Madrid, 1996-2006). In: GARCÍA GALLARÍN, C. Los nombres del Madrid multicultural. Madrid: Parthenon, 2007. p. 99-134.

GERRITZEN, D. Naming Children in a Globalizing World. Acta Onomastica, v. XLVII, p. 177-184, 2006.

GUÉRIOS, R. F. M. Dicionário etimológico de nomes e sobrenomes. 2. ed. São Paulo: Ave Maria, 1972.

GUÉRIOS, R. F. M/ MANSUR, R. F.. Dicionário etimológico de nomes e sobrenomes. 3. ed. São Paulo: Ave Maria, 1981.

IBGE. Instituto Brasileiro de Geografia e Estatística. 2020. Disponível em: https://www.ibge.gov.br/. Acesso em: 18 ago. 2021.

INE. 2020. Instituto Nacional de Estadística de España. 2020. Disponível em: www.ine.es. Acesso em: 18 ago. 2021.

JIMÉNEZ SEGURA, S. Los procesos de cambio de los modelos de atribución antroponímica tradicional y a partir de la moda en el municipio de Tlalnepantla de Baz, Estado de México. Tres calas: 1930, 1960 Y 1990. Trama, p. 10-20, 2014.

JOSEPH, J.E. Language and identity. New York: Palgrave Macmillan. 2004.

LAWSON, E. Semantic differential analysis of men's first names. The Journal of Psychology: Interdisciplinary and Applied, v. 78, n. 2, p. 229-240, 1971.

LIEBERSON, S. A matter of taste. How names, fashions, and culture change. New Haven: Yale University Press, 2000.

LIEBERSON, S.; BELL, E. Children's first names: an empirical study of social taste”. American Journal of Sociology, v. 98, n. 3, p. 511 $554,1992$.

LÓPEZ FRANCO, Y. Comparaison des prénoms attribués en 1970 et 1975 dans deux comunes romanophones: Tlalnepantla de Baz au Mexique, et Montpellier en France. Une approche socioanthroponymique. In: TORT I DONADA, J.; MONTAGUT I MONTAGUT, M. Els noms en la vida quotidiana. Actes del XXIV Congrés Internacional d'ICOS sobre Ciències Onomàstiques. Barcelona: Generalitat de Catalunya, 2014. Secció 3. Disponible en: http://www.gencat.cat/llengua/BTPL/ICOS2011. Acceso en: 30 jul. 2020 . 
LÓPEZ FRANCO, Y. Las relaciones intercategoriales e intracategoriales en antroponimia. El caso de los nombres de pila en francés de Francia y en español de México. Revista Onomástica desde América Latina, n.1, v.1, p.214-219, 2020. Disponible en http://erevista.unioeste.br/index.php/onomastica. Acceso en: 30 jul. 2020.

MitZlafF, F.; STUMme, G. Onomastics 2.0 - The Power of Social Co-Occurrences. ArXiv, 2013. Disponible en: https://arxiv.org/abs/1303.0484v1. Acesso en: 30 jul. 2020.

MORANT MARCO, R. Denominación, alternancia onomástica y redenominación de animales domésticos. RILCE, v. 32, n.1, p. 201-224. 2016.

ORTEGA-OJEDA, G. La competencia onomástica dialectal, a propósito del caso canario. Revista de Filologia de la Universidad de La Laguna, n.13, p. 291-307, 1994.

PIEL, J.M. Estudos de Linguística Histórica Galego-Portuguesa. Lisboa: Imprensa Nacional. 1986.

ROSSI, A. Naming Children in Middle-Class Families. American Sociological Review n. 30, p. 499-513, 1965.

SEIDE, M. S. Métodos de pesquisa em Antroponomástica. Domínios de Lingu@gem, Uberlândia, v. 10, n.3, p. 1146-1171, 2016.

SEIDE, M. S. A Antroponomástica Comparada. Onomástica desde América Latina, v.1, n.2, p.82-101, 2020. Disponible en http://erevista.unioeste.br/index.php/onomastica. Acceso en: 30 jul. 2020.

SEIDE, M. S. Prenomes cristãos: constituição, etimologia, motivação para a escolha antroponímica e conhecimento onomástico. Revista Estudos da Linguagem, v.29, n.1 2021.

SEIDE, M. S.; FRAI, P. H. Antroponímia comparada: um estudo sobre os nomes inovadores na antroponímia da Espanha e do Brasil. Afluente: revista de Letras e Linguística.v.4, n.12, p. 64-86, 2019

SEIDE, M. S. ; PETRULIONĖ, L. Between languages and cultures: an exploratory comparative study of usage of Lithuanian and Brazilian Masculine Anthroponyms. Revista de Estudos da Linguagem, v. 26, n.3, p. 1201-1226, 2018. Disponible en: http://www.periodicos.letras.ufmg.br/index.php/relin/issue/view/635. Acceso en: 30 jul. 2020.

SIMÕES NETO, N. A.; SOLEDADE, J. Nomes masculinos X-son na antroponímia brasileira: uma abordagem morfológica, histórica e construcional / Male Names in X-Son in Brazilian Anthroponymy: a Morphological, Historical and Constructional Approach. Revista de Estudos da Linguagem, v. 26, n. 3, p. 1295-1350. $2018 . \quad$ Disponible en http://www.periodicos.letras.ufmg.br/index.php/relin/issue/view/635.Acceso en: 30 jul. 2020.

SOLEDADE, J. J. A antroponímia no português arcaico: aportes sobre a sufixação em nomes personativos. In: LOBO, T. et al. Rosae: linguística histórica, história das línguas e outras histórias [online]. Salvador: EDUFBA, 2012. p. 323-336. Disponible em: http://books.scielo.org. Acceso em: 30 jul. 2020.

TWENGE, J.M., E. ABEBE y W.K. CAMPBELL. Fitting In or Standing Out: Trends in American Parents' Choices for Children's Names, 1880-2007, Social Psychological and Personality Science 1, p. 19-25. 2010.

VANDEBOSCH, H. The influence of media on given names. Names, n. 46, p. 243-262. 1998.

WEITMAN, S. Some methodological issues in quantitative onomastics, Names, v. 29, n.3, p. 181-196. 1981. 
XI, N. et al. Cultural evolution: The case of babies' first names”. Physica A: Statistical Mechanics and its Applications, n. 406, p. 139144. 2014.

\section{() (1) $@ \odot$}

Recibido el 15/05/2020. Aceptado el 30/07/2020. 